\title{
Caribbean parkinsonism
}

INSERM

\section{Source}

INSERM. (1999). Orphanet: an online rare disease and orphan drug data base. Caribbean parkinsonism. ORPHA:97355

Parkinsonism with dementia of Guadeloupe is characterised by symmetrical bradykinesia, predominantly axial rigidity, postural instability with early falls and cog nitive decline with prominent features of frontal lobe dysfunction. 